\title{
ARTIFICIAL NEURAL NETWORK BASED MODEL OF PHOTOVOLTAIC CELL
}

\author{
Messaouda AZZOUZI' ${ }^{1}$, Lakhdar BESSISSA ${ }^{1}$ \\ Mona Fouad MOUSSA 2 \\ Dumitru POPESCU ${ }^{3}$ and Catalin PETRESCU ${ }^{3}$ \\ ${ }^{1}$ Faculty of Sciences and Technology, University of Djelfa BP 3117 Djelfa 17.000, Algeria Faculty of Automatic Control and \\ Computers \\ ${ }^{2}$ Arab Academy for Science and Technology and Maritime Transport (AASTMT) Smart Village Campus, Cairo, Egypt \\ ${ }^{3}$ University Politehnica of Bucharest, Splaiul Independentei nr. 313,sector6, Bucuresti, Romania \\ Dr.Azzouzi@yahoo.fr, I_bessissa2001@yahoo.fr, mona.moussa@yahoo.com, \\ popescu_upb@yahoo.com, catalin.petrescu@acse.pub.ro
}

\begin{abstract}
This work concerns the modeling of a photovoltaic cell and the prediction of the sensitivity of electrical parameters (current, power) of the six types of photovoltaic cells based on voltage applied between terminals using one of the best-known artificial intelligence technique, which is the Artificial Neural Networks. The results of the modeling and prediction have been shown and then compared between them. NEWFF learning algorithm was used with specified number of iteration that gave the best results. The error was calculated in all cases to check the accuracy of the used method.
\end{abstract}

\section{Keywords -}

PV: Photovoltaic

I-V: current-voltage

P-V: power-voltage

NEWFF:Feed Forward Multilayer Perceptron Network

L3P: Lumped, one mechanism, Three Parameters

L4P: Lumped, one mechanism, Four Parameters

L5P: Lumped, one mechanism, Five Parameters

2M5P: Two Mechanisms, Five Parameters

2M6P: Two Mechanisms, Six parameters

2M7P: Two Mechanisms, Seven Parameters

$\mathrm{I}_{\mathrm{ph}}[\mathrm{A}]: \quad$ the current generated by the incident light

$I_{s}[A]: \quad$ the diode reverse bias saturation current

$I_{\text {sh }}[A]$ : the shunt resistance current

$\mathrm{I}_{\mathrm{sc}}[\mathrm{A}]$ : $\quad$ short circuit current of the PV cell

Isco: short circuit current of the PV cell under standard conditions

$\operatorname{lpv}[A]: \quad$ the output current

$\mathrm{V}_{\mathrm{pv}}[\mathrm{V}]$ : the terminal voltage

$\mathrm{V}_{\mathrm{ph}}[\mathrm{V}]$ : the photovoltaic voltage

$\mathrm{V}_{\mathrm{oc}}[\mathrm{V}]$ : open circuit voltage

q: $\quad$ the electron charge

$\mathrm{k}$ : the Boltzmann constant

$\mathrm{T}[\mathrm{K}]$ : the temperature of the PN junction
$\mathrm{T}_{0}$ : $\quad$ standard temperature

Eg: energy gap

$\mathrm{E}\left[\mathrm{W} / \mathrm{m}^{2}\right]$ : the irradiation

$\mathrm{E}_{0}$ : $\quad$ standard irradiation

$\mathrm{R}_{\mathrm{s}}[\Omega]$ : $\quad$ series resistance

$\mathrm{R}_{\text {sh }}[\Omega]$ : $\quad$ shunt resistance

$\mathrm{n}$ : the ideality factor of the diode

$\mathrm{I}_{\mathrm{s} 1}[\mathrm{~A}]:$ the first diode reverse bias saturation current

$I_{s 2}[A]: \quad$ the second diode reverse bias saturation current

$I_{\text {sh }}[A]:$ the shunt resistance current

$\operatorname{ld}[A]: \quad$ the diode current

$I_{d 1}[A]: \quad$ the first diode current

$I_{d 2}[A]: \quad$ the second diode current

$\mathrm{m}_{1}$ : $\quad$ the ideality factor of the first diode

$\mathrm{m}_{2}$ : the ideality factor of the second diode

$\mathrm{V}_{\mathrm{t}}=\frac{\mathrm{KT}_{\mathrm{c}}}{\mathrm{q}}$ : thermodynamic potential

$T_{c}$ : the actual temperature of the cell temperature

$\mathrm{T}_{\mathrm{c}_{\mathrm{ref}}}$ : the cell temperature at reference conditions

$I_{\text {sref }}[\mathrm{A}]$ : the saturation current at reference conditions

k1, k2: constants

$\mathrm{S}_{\mathrm{j}}$ : weighted amount to the input of neuron $\mathrm{j}$ of the layer (I)

$\mathrm{N}^{\mathrm{l}}$ : $\quad$ number of the neuron of the layer $(\mathrm{I})$

$\mathrm{u}_{\mathrm{j}}^{\mathrm{l}}$ : $\quad$ output of the neuron $\mathrm{j}$ of the layer (I)

$\mathrm{w}_{\mathrm{ji}}^{\mathrm{l}}$ : $\quad$ weight that connects neuron $\mathrm{i}$ of the layer $(\mathrm{I}-1)$ with the neuron $\mathrm{j}$ of the layer (I)

$\mathrm{L}$ : $\quad$ number of layers in the network. Layer (0) corresponds to the input nodes

$f($.$) : activation function.$

Erl: current error

ErP: power error

\section{INTRODUCTION}

Artificial neural networks have attracted the attention of a large number of researchers in the field of 
renewable energies, and in particular for the modeling of photovoltaic cells [1].

Indeed, much research has proved the ability of neural networks to model PV cells. They have shown that they are more appropriate, and give better results compared to the conventional approximation methods proposed by other researchers, for the modeling of PV cells [2].

The purpose of this paper is to find the most precise mathematical models in order to obtain an optimal dimensioning of the PV cells using artificial neural networks [3]. The work was organized in three parts:

- In the first part, we discussed the six different models of a solar cell.
- The second part presents a definition of artificial neural networks with their mathematical equations.

- The third part is devoted to modeling and thus predicting a photovoltaic cell by artificial neural networks then validating the results by calculating the error.

\section{MODELING OF SOLAR CELL}

A photovoltaic cell can be described simply as an ideal source of courant which produces a current Iph proportional to the incident light power after being exposed to solar radiation. The equivalent circuit diagrams of the PV cell for the different models of PV cell are represented in the following figure [1][2].

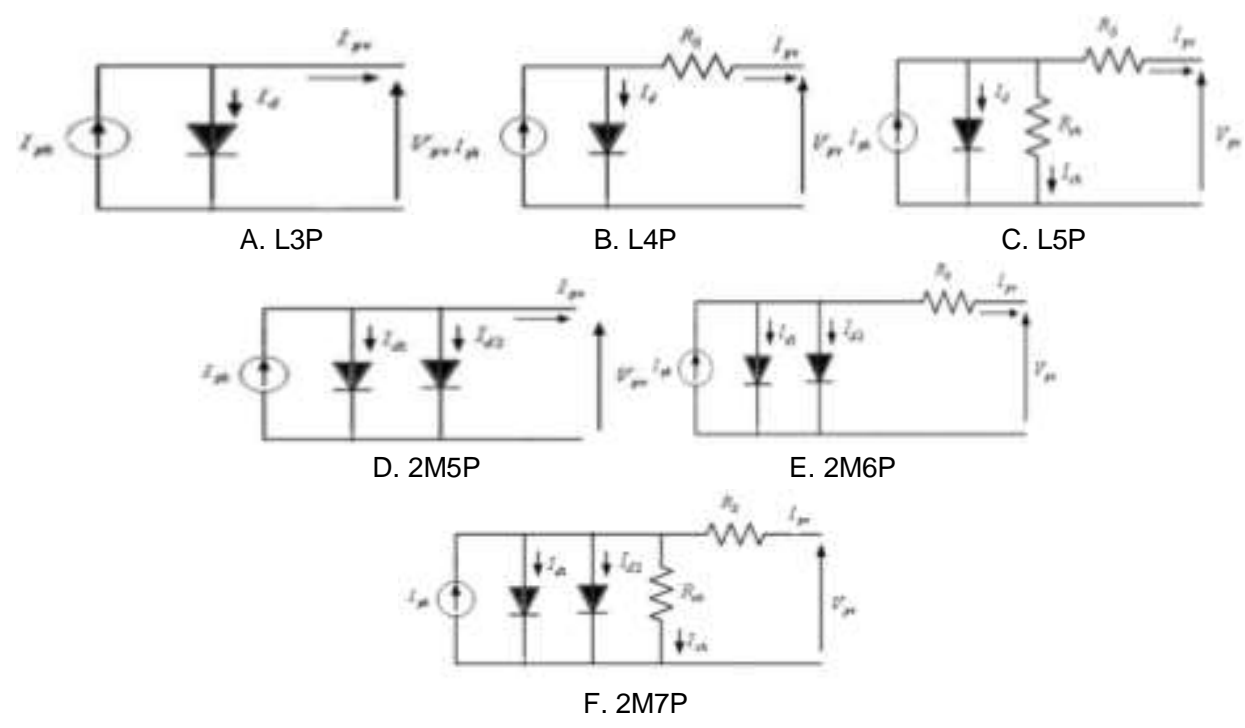

Fig.1. Equivalent diagram of the different models of a solar cell

The characteristic equation is derived in a straightforward manner from the law of kirchhoff:

$\mathrm{I}_{\mathrm{pv}}=\mathrm{I}_{\mathrm{ph}}-\mathrm{I}_{\mathrm{d}}$

The diode is a nonlinear element; the IV characteristic is given by the relation:

$I_{d}=I_{s}\left(\exp \left(\frac{V_{d}}{V_{t}}\right)-1\right)$

The debited current is equivalent to:

$$
I_{p v}=I_{p h}-I_{s}\left(\exp \left(\frac{V_{p v}}{V_{t} \cdot n}\right)-1\right)
$$

The saturation current of the diode is assumed to vary with temperature according to the expression:

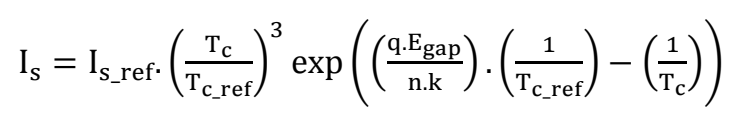

a) Short-circuit I current Icc

It is the current for which the voltage across the PV cell is zero $\left(\mathrm{V}_{\mathrm{pv}}=0\right)$.

$\mathrm{I}_{\mathrm{CC}}=\mathrm{I}_{\mathrm{pv}}=\mathrm{I}_{\mathrm{ph}}$

b) Open circuit voltage $V_{c o}$

This is the voltage at which the debited current by the PV cell is zero expression. Its expression is derived 
from equation (3) by canceling the current $\left(\mathrm{l}_{\mathrm{pv}}=0\right)$

$$
\mathrm{V}_{\mathrm{pv}}=\mathrm{V}_{\mathrm{co}}=\mathrm{V}_{\mathrm{t}} \cdot \mathrm{n} \cdot \ln \left(1+\frac{\mathrm{I}_{\mathrm{CC}}}{\mathrm{I}_{\mathrm{s}}}\right)
$$

The electric power $\mathrm{P}(\mathrm{W})$ provided to the terminals of a $P V$ cell is equal

$$
P=\mathrm{V}_{\mathrm{pv}}\left[\mathrm{I}_{\mathrm{CC}}-\mathrm{I}_{\mathrm{s}}\left(\exp \left(\frac{\mathrm{V}_{\mathrm{pv}}}{\mathrm{n} \cdot \mathrm{V}_{\mathrm{t}}}\right)-1\right)\right]
$$

The L4P model treats the photovoltaic cell as a dependent current source of illumination, connected in parallel with a diode and in series with a series resistance Rs. Electric current produced by the cell is then given by the following expression [3]:

$$
I_{p v}=I_{p h}-I_{s}\left(\exp \left(\frac{V_{p v}+I_{p v} \cdot R_{s}}{n \cdot V_{t}}\right)-1\right)
$$

In the case of L5P, losses are modeled by two resistances, shunt resistance and the series resistance. The model thus involves the following five unknown parameters: n, Iph, Rs, Rsh and Is [4].

The characteristic equation is derived in a straightforward manner from the law of Kirchhoff

$$
I_{p v}=I_{p h}-I_{d}-I_{s h}
$$

The electric current produced by the cell is:

$$
I_{p v}=I_{p h}-I_{s}\left(\exp \left(\frac{V_{p v}+I_{p v} \cdot R_{s}}{n \cdot V_{t}}\right)-1\right)-\left(\frac{V_{p v}+I_{p v} \cdot R_{s}}{R_{s h}}\right)
$$

The operation of a solar cell can be modeled by considering the parallel connection of two diodes having saturation currents Is 1 and Is2, the diode factors $\mathrm{n} 1$ and $\mathrm{n} 2$, a current source generating a photocurrent Iph, which depends on solar irradiation [5][6].

The characteristic equation is derived in a straightforward manner from the law of kirchhoff:

$I_{p v}=I_{p h}-I_{d 1}-I_{d 2}-I_{s h}$

The diode is a nonlinear element, the IV characteristic is given by equation:

$$
\begin{aligned}
& I_{d 1}=I_{s 1}\left(\exp \left(\frac{v_{d}}{n_{1} \cdot V_{t}}\right)-1\right) \\
& I_{d 2}=I_{s 2}\left(\exp \left(\frac{V_{d}}{n_{2} \cdot V_{t}}\right)-1\right) \\
& I_{s h}=\frac{V_{p v}+I_{p v} \cdot R_{s}}{R_{s h}}
\end{aligned}
$$

The electric current produced by the 2M5P cell is then given by the following expression:

$$
\begin{aligned}
& I_{p v}=I_{p h}-I_{s 1}\left(\exp \left(\frac{V_{p v}+I_{p v} \cdot R_{s}}{n_{1} \cdot V_{t}}\right)-1\right)-I_{s 2}\left(\exp \left(\frac{V_{p v}+I_{p v} \cdot R_{s}}{n_{2} \cdot V_{t}}\right)-1\right)- \\
& \left(\frac{V_{p v}+I_{p v} \cdot R_{s}}{R_{s h}}\right)
\end{aligned}
$$

It involves the mathematical description of a circuit realized by the parallel connection of two diodes having the saturation currents $I_{\mathrm{S} 1}$ and $I_{\mathrm{s} 2}$, diodes factors $n_{1}$ and $n_{2}$, a current source generating a photocurrent Iph that is dependent on the solar irradiance and RS series resistance [7][8].

It The characteristic equation is derived in a straightforward manner from the law of Kirchhoff:

$\mathrm{I}_{\mathrm{pv}}=\mathrm{I}_{\mathrm{ph}}-\mathrm{I}_{\mathrm{d} 1}-\mathrm{I}_{\mathrm{d} 2}$

The electric current produced by the 2M6P cell is then given by the following expression

$I_{p v}=I_{p h}-I_{s 1}\left(\exp \left(\frac{V_{p v}+I_{p}, R_{s}}{n_{1} V_{t}}\right)-1\right)-I_{s 2}\left(\exp \left(\frac{V_{p v}+I_{p}, R_{s}}{n_{2} V_{t}}\right)-1\right)$

The equivalent circuit model 2M5P is obtained using the simplified circuit model which has six parameters (Lumped, 2 Mechanism model with 5 parameters) [9][10]. It is achieved by mathematical description in parallel connection of two diodes having its saturation current IS1 and IS2, the diode factors n1 and n2, a current source generating a photocurrent Iph that depends on the solar irradiance and temperature [16]. The characteristic equation is derived in a straightforward manner from the law of Kirchhoff [18][19] :

$I_{p v}=I_{p h}-I_{d 1}-I_{d 2}$

The electric current produced by the cell is then given by the following expression:

$I_{p v}=I_{p h}-I_{s 1}\left(\exp \left(\frac{V_{p v}}{n_{1} \cdot V_{t}}\right)-1\right)-I_{s 2}\left(\exp \left(\frac{V_{p v}}{n_{2} \cdot V_{\mathrm{t}}}\right)-1\right)$

\section{ARTIFICIAL NEURAL NETWORK}

Artificial neurons are the artificial intelligence technique most commonly used in the field of modeling and control methods. They consist of a precise number of neurons that are arranged in layers. Neurons of two adjacent layers are interconnected by weight, using the NEWFF algorithm 
with variable number of iterations, after many experiences we found that the number of 150 iterations gave the most appropriated results[11] [12]. The figure (2) shows an example of artificial neural network.

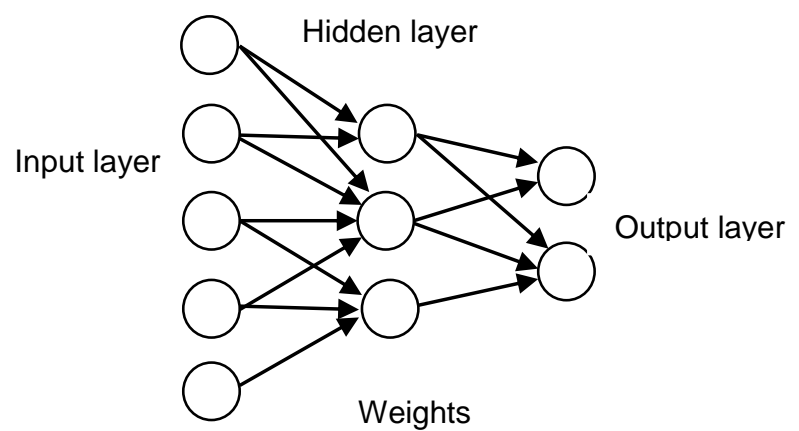

Fig.2. Architecture of the ANN

The multilayer perceptron is probably the simplest and most well-known neural network. It consists of several

connected layers of neurons. The activation function is mainly used sigmoid function.

Consider the neural network MLP "Multi-Layer Perceptron" $L$ layer $P$ inputs and q outputs. The input layer contains the components of the input vector $\left(\mathrm{x}_{\mathrm{i}}\right)$
$0 \leq \mathrm{i} \leq \mathrm{p}$.

The calculations are made layer by layer from the input to the output.

The output of the neuron $j$ of the layer $I(0<I \leq L)$ is given by:

$s_{j}^{l}=\sum_{i=0}^{N^{l-1}} w_{j i}^{l} \cdot u_{i}^{l-1}$

$u_{j}^{l}=f\left(s_{j}^{l}\right)$

It is noted that the first element of each vector $u^{l}(1=0,1, \ldots L-1)$ is set at one (i.e., $\left.u_{0}^{1}=1\right)$ and the product $\left(\mathrm{w}_{\mathrm{j} 0}^{\mathrm{l}} * \mathrm{u}_{0}^{\mathrm{l}-1}\right)$ represents the value of the internal threshold of the neuron $j$ in the layer [15][17]

\section{MODELING AND PREDICTION OF THE PV CELL POWER}

The experimental data of current and power versus the voltage was loaded on Matlab to be compared to the obtained results. Each time the neural network is trained. In Fig. 3 the model and the prediction follow the curves of experimental data with a minimum error for different models. The error increases in case of prediction.
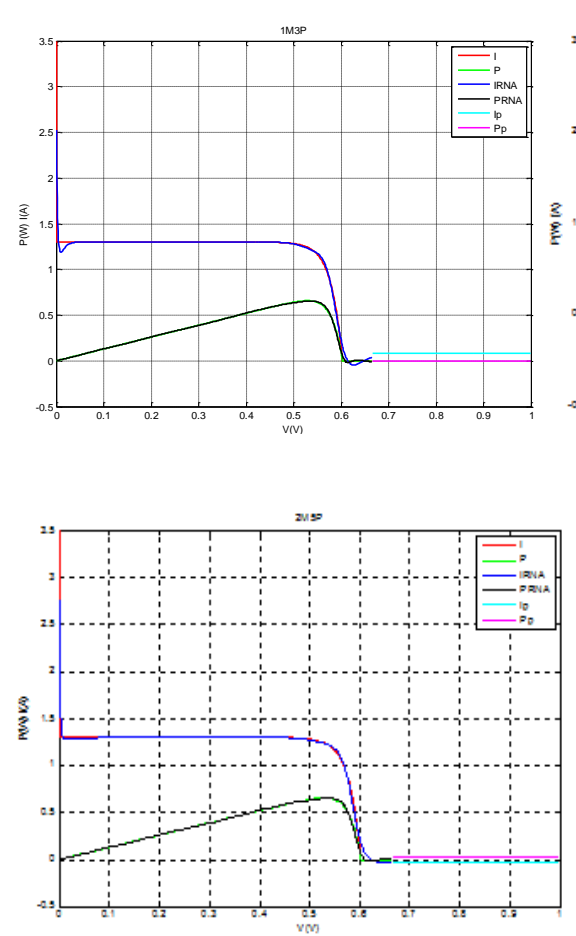

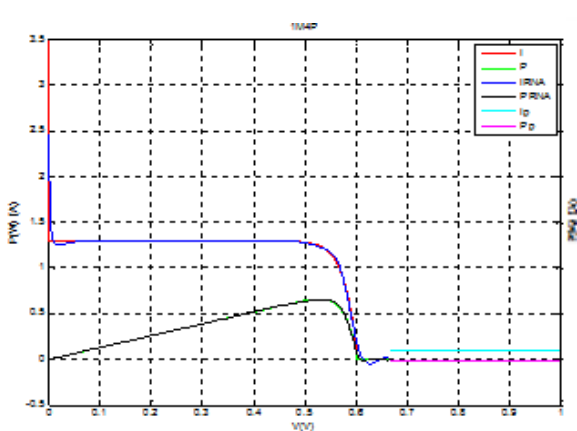

a. Single diode cell

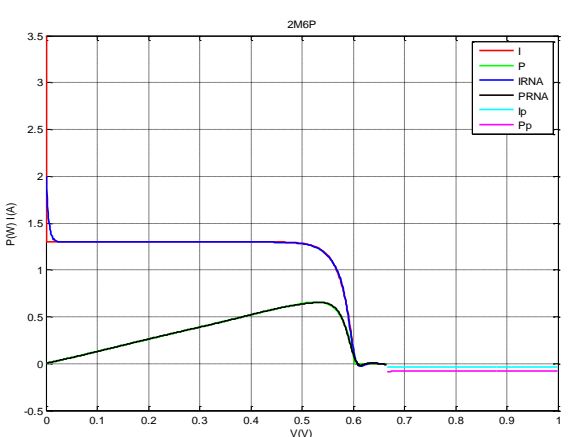

b. Double diode cell
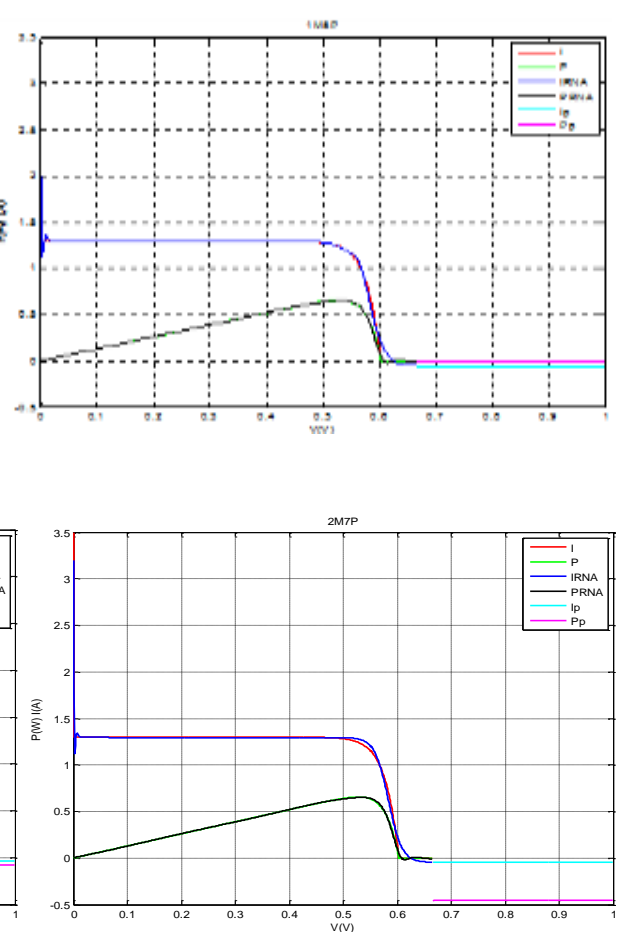

Fig.3. Modeling and prediction of current and the power 


\section{COMPARING THE PERFORMANCE OF PV CELLS}

The following table shows that current errors are almost zero, and the L4P model is better because the error is close to zero, but in the prediction there is a remarkable difference. Power errors are zero even in prediction. These of the two models 1M4P and L3P are zero white the error the L5P model increases.

When we compare the results of double diode models. The 2M7P model is the best one. In the prediction, there is a remarkable difference; we note that errors of the two models 2M5P and 2M6P are zero against the error of the 2M7P model which increases.

The current errors are larger than those of the models with double diode. The 2M7P model is the best, and in the prediction, there is a remarkable distance. We note also that the power errors are zero even in prediction. Errors of the two models 2M5P and 2M6P are zero against the error of the 2M7P model which increases.

\begin{tabular}{|c|c|c|c|c|c|c|c|c|c|c|c|c|c|c|c|c|c|c|}
\hline 믄 & 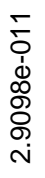 & 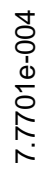 & 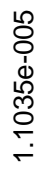 & 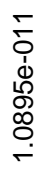 & 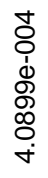 & 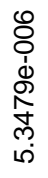 & 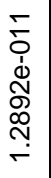 & 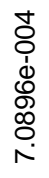 & 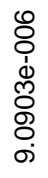 & 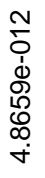 & 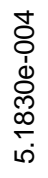 & 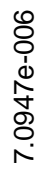 & 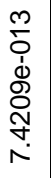 & 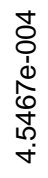 & 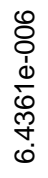 & $\begin{array}{l}\text { N } \\
0 \\
d \\
\frac{1}{0} \\
\frac{6}{10} \\
\frac{1}{0}\end{array}$ & 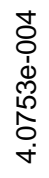 & 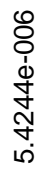 \\
\hline 亡ั & 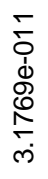 & \begin{tabular}{l}
0 \\
\multirow{8}{0}{} \\
0 \\
0
\end{tabular} & 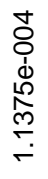 & 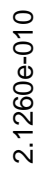 & 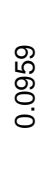 & \begin{tabular}{l} 
ঠे \\
d \\
$d$ \\
$\stackrel{N}{N}$ \\
\multirow{J}{o}{} \\
$\stackrel{N}{ }$
\end{tabular} & 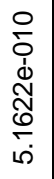 & $\begin{array}{c}\stackrel{\mathfrak{d}}{N} \\
0 \\
0\end{array}$ & $\begin{array}{l}\bar{\sigma} \\
\stackrel{8}{8} \\
\circ\end{array}$ & 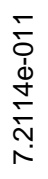 & 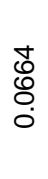 & 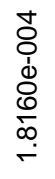 & 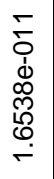 & $\begin{array}{l}\underset{\mathbb{N}}{N} \\
0\end{array}$ & $\begin{array}{l}\bar{\sigma} \\
8 \\
0\end{array}$ & 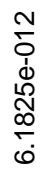 & $\begin{array}{l}\stackrel{d}{N} \\
\vdots \\
0\end{array}$ & 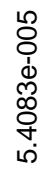 \\
\hline $\begin{array}{l}\text { 흔 } \\
\text { 亡े }\end{array}$ & $\stackrel{\leftrightarrows}{\Sigma}$ & $\stackrel{\times}{\Sigma}$ & $\stackrel{0}{\Sigma}$ & $\stackrel{\subseteq}{\Sigma}$ & $\stackrel{\times}{\Sigma}$ & $\stackrel{\partial}{\Sigma}$ & $\stackrel{\stackrel{5}{\Sigma}}{\Sigma}$ & 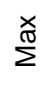 & $\sum^{\frac{\partial}{2}}$ & $\stackrel{5}{\sum}$ & $\stackrel{\times}{\Sigma}$ & $\stackrel{D}{\Sigma}^{\frac{0}{2}}$ & $\stackrel{5}{\Sigma}$ & 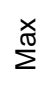 & $\sum^{\frac{D}{2}}$ & $\stackrel{\subseteq}{\Sigma}$ & 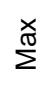 & $\stackrel{\partial}{\Sigma}$ \\
\hline $\begin{array}{l}\overline{0} \\
\overline{0} \\
\text { 일 }\end{array}$ & \multicolumn{3}{|c|}{ ले } & \multicolumn{3}{|c|}{$\stackrel{\text { 导 }}{ }$} & \multicolumn{3}{|c|}{ مِ } & & \multicolumn{2}{|c|}{$\sum_{N}^{0}$} & \multicolumn{3}{|c|}{$\sum_{N}^{0}$} & \multicolumn{3}{|c|}{$\sum_{\text {N }}^{\stackrel{n}{N}}$} \\
\hline & \multicolumn{9}{|c|}{ Single diode } & \multicolumn{9}{|c|}{ Double diode } \\
\hline
\end{tabular}

Table. 1. Current and power errors of PV single and double diode cell

\section{CONCLUSION}

This work presents the modeling of the problem of six photovoltaic modules using artificial neural networks. Also one presented the basic electrical characteristics of a photovoltaic cell and the equivalent circuits were described.

The comparison results of the performance of PV cells with a single diode and two diodes indicates that the prediction error increases when adding the shunt resistor i.e. in case of the two models L3P and 2M7P. On the other hand, the current error is generally greater than the power error in all the models. These results confirm the ability of artificial neural networks to modeling of photovoltaic cells.

\section{REFERENCES}

[1] Initial. Zekai. «Sen. solar energy fundamentals and mode ling techniques.» Springer, 2008, pp. 15-25.
[2] V. Badescu. «Modeling solar radiation at the earth's surface.» Springer, 2008, pp. 10-21.

[3] M. Chegaar, A. Lamir and A. Chibani. «Estimation global solar radiation using sunshine hours.» 4éme séminaire International Physique Energétique, Bechar ,2000.

[4] International Physique Energétique, Bechar, 2000.

[5] W. Omran. Performance analysis of grid connected photovoltaic systems. These de Doctorat, Université de Waterloo, 2010.

[6] D. U. Sauer. «Electrochemical storage for photovoltaics» Fraunhofer Institute for Solar Energy Systems ISE, Freiburg, Germany, 2004.

[7] D. Thévenard and M. Ross. "Validation and verification of component models and system 
models for the PV.» CETC-internal report 2003035, Canada, 2003.

[8] G. Notton et al. «Influence d'un ombrage partiel sur la production électrique d'un module photovoltaïque es silicium monocristallin.» Revue des énergies renouvelables, vol.13, no.1, pp. 4962, 2010.

[9] T. Townsend. A Method for estimating the long term performance of direct coupled photovoltaic systems. MS Thesis, solar energy laboratory, university of Wisconsin, Madison, 1989.

[10] R. Roshanak. Réalisation et caractérisation des cellules solaires organiques à couche composites polymères incluant des nanotubes de carbones. Thèse de Doctorat de l'Université de Limoges, 2008.

[11] R. Khezzar et al. "Comparaison entre les différents modèles électriques et détermination des paramètres de la caractéristique I-V d'un module photovoltaïque.» Revue des énergies renouvelables, vol.13, no.3, pp. 379-388, 2010.

[12] C. Bishop. Neural networks for pattern recognition. Oxford University Press, 1995.

[13] D. Dreyfus, J-M. Martinez, M. Samuelides, M. B. Gordon, F. Badran, S. Thiria and L. Hérault. "Réseaux de neurones.» Méthodologie et applications, Eyrolles, 2ème édition, 2004, pp. 12-35.
[14] J. Hopfield. «Neural networks and physical systems with emergent collective computational abilities.» Proceedings of the National Academy of Sciences. vol.79, pp. 2554-2558,1982.

[15] J. Molga. «Neural network approach to support modelling of chemical reactors.» Chemical Engineering and Processing, vol.42, pp. 675-695, 2003.

[16] N. Delgrange, C. Cabassud, M. Cabassud, L. Durand-Bourlier and J. Lainé. «Neural networks for prediction of ultrafiltration transmembrane pressure.» Application to drinking water production, Journal of Membrane Science, 150, pp. 111-123, 1998.

[17] G. Dreyfus and Y. Idan. "The canonical form of discrete-time non-linear models.» Neural Computation, complete the data.

[18] H. White. Artificial neural networks. Blackwell, New York, 1992.

[19] K. Helali. Modélisation d'une cellule photovoltaïque: étude comparative. Mémoire de Magister de l'Université de Tizi-Ouzou, 2011. 